\title{
LETTER
}

doi:10.1017/\$1041610212001639

\section{Euthanasia and physician-assisted suicide in Huntington's disease in The Netherlands}

Huntington's disease (HD) is a progressive autosomal dominant neurodegenerative disease characterized by chorea, hypokinesia, psychiatric symptoms, and dementia. The age of onset is usually between 30 and 50 years; the duration of illness is from 10-20 years. The rate of suicide in patients is higher than in the general population and is the second most common cause of death in HD after pneumonia (Bindler et al., 2009). Currently, symptomatic treatment is available, but there is no cure. The identification of HD-gene in 1993 made DNA testing possible in individuals at risk.

In the Netherlands the codification of the Termination of Life on Request and Assisted Suicide Act in 2002 (2002 Law) legalized euthanasia under strict conditions. Between 2007 and January 2011, $30 \mathrm{HD}$ patients died as a result of euthanasia or physician-assisted suicide (PAS), which is equivalent to approximately $7 \%$ of deaths from the condition HD (www.euthanasiecommissie.nl).

Huntington's disease and other neurodegenerative diseases differ from conditions such as cancer regarding mean duration and cognition. A third important difference is the fact that many $\mathrm{HD}$ patients know the characteristics and the course of the disease.

In our university clinic, with a focus on movement disorders, the number of requests from HD patients for euthanasia or PAS, and advance directives concerning this issue, seems to be increasing. Apart from clinical experience and anecdotal data, to our knowledge no systemic studies have been carried out on euthanasia or PAS in HD. In this letter we discuss the role of advance directives in $\mathrm{HD}$, focusing on two main conditions of the 2002 Law.

The 2002 Law states two main requirements of due care within which a physician must abide. These conditions are "know that the request was voluntary and carefully considered" and "the patient's suffering was unbearable and without prospect of improvement, and there is no reasonable alternative."

1. The first condition of the law requires exploration of the request by the physician. A competent patient can express his wish and make a formal request for euthanasia or PAS in advance, to be carried out when the patient becomes incompetent and loses his decisionmaking capacities, as long as the other requirements of the law are met (de Boer et al., 2010b).

Initially, advance directives for euthanasia were intended to apply to patients with dementia. The validity of these advance directives is currently a matter of debate. In patients with dementia, the insidious progression allows them to adapt to the disease and this can cause a change of opinion, called response shift (de Boer et al., 2010b).

Second, in $200654 \%$ of physicians in the Netherlands reported that they would not perform euthanasia based on an advance directive in a patient with Alzheimer's Disease (AD) (Rurup et al., 2005). Their reluctance was not only based on legal arguments or a lack of knowledge about the conditions and interpretation of the law, but, we suspect, also an emotional argument.

The elements of response shift, the accuracy of the wish, and increasing incompetence in a disease, such as HD, make the drafting of an advance directive difficult. But since so much is known about the symptoms and signs, advance directives can be a good way of documenting at least the present wish. And in the first case of euthanasia to reach the Supreme Court (case of Dr. Schoonheim), the court stated that when considering a request for euthanasia or PAS, "the physician has to take personality, intelligence and history of the patient into account."

2. The second condition is "suffering." In the ruling of Dr. Schoonheim, the Court stated that "the prospect of unbearable suffering, progressive deterioration and when knowing that dying with dignity is possible now, but most likely not in the future can qualify as suffering." The point at which the suffering becomes unbearable is a decision that only a patient can make.

The legislation regarded the qualification "without prospect" as being when there are no adequate alternative management options for the disease, i.e. there are no ways to relieve, ease, or undo the suffering. Alternative solutions can be decided upon before the euthanasia request becomes pressing. The decision that there is no solution other than euthanasia is a joint conclusion of the patient and his physician.

Although an aspect of dementia is a decline in the realization of cognitive deficits, studies with patients in the early stages of $\mathrm{AD}$ showed an awareness of their failing memory, and also that conversations concerning advance care planning 
could be possible (de Boer et al., 2010a). In HD, physical and psychiatric symptoms and complete dependency can be the prevailing signs. In this case $\mathrm{HD}$ patients remain cognitively able to comprehend their situation as suffering.

In 2009, in the Netherlands, euthanasia based on an advance directive was performed on one patient, which was declared accurate and careful. The physician stated that it would be disrespecting the patient's autonomy to leave him in a situation that he wished to avoid and considered as unbearable suffering. The advance directive was regularly discussed between physician and patient over a period of several years (www.euthanasiecommissie.nl).

This ruling provides an example of the options of euthanasia or PAS in HD. Especially, the pre-manifest phase is a stage when it is appropriate for the patient to explore and articulate his/her wishes with his physician and deal with future incompetence by making an advance directive describing the suffering. Implementation would take place when the patient reaches the stage mentioned in the advance directive.

Further, clinical knowledge is required to gain greater insight into the patient's motives for requesting euthanasia or PAS and to determine the role of advance directives. We also need to study the attitudes and moral considerations of physicians involved in this specific patient population. When there is no cure and few means of improving the quality of life, discussing end-of-life wishes can also be a way of guiding and treating your patient.

\section{Conflict of interest}

None.

\section{References}

Bindler, L., Travers, D. and Millet, B. (2009). Suicide in Huntington's disease: a review. Revue Médicale Suisse, 5, 646-648. available at PM:19365916.

de Boer, M. E., Droes, R. M., Jonker, C., Eefsting, J. A. and Hertogh, C. M. (2010a). The lived-experiences of early-stage dementia and the feared suffering: an explorative survey. Tijdschrift Voor Gerontologie En Geriatrie, 41, 194-203. available at: PM:21114055.

de Boer, M. E., Hertogh, C. M., Droes, R. M., Jonker, C. and Eefsting, J. A. (2010b). Advance directives in dementia: issues of validity and effectiveness. International Psychogeriatrics, 22, 201-208. available at: PM:19664311.

Rurup, M. L., Onwuteaka-Philipsen, B. D., van der Heide, A., van der Wal, G. and van der Maas, P. J. (2005). Physicians' experiences with demented patients with advance euthanasia directives in the Netherlands. Fournal of the American Geriatrics Society, 53, 1138-1144. available at: PM:16108931.

Suzanne J. Booij, ${ }^{1}$ Dick P. Engberts, ${ }^{2}$ Aad Tibben ${ }^{3}$ and Raymund A. C. Roos ${ }^{1}$

${ }^{1}$ Department of Neurology, Leiden University Medical Centre (LUMC), Leiden, The Netherlands

${ }^{2}$ Section of Medical Ethics and Health Law, Leiden University Medical Centre (LUMC), Leiden, The Netherlands

${ }^{3}$ Section for Genetic Counselling, Centre for Human and Clinical Genetics, Leiden University Medical Centre (LUMC), Leiden, the Netherlands Email: s.j.booij@lumc.nl 